\title{
Cell cycle-dependent Cdc25C phosphatase determines cell survival by regulating apoptosis signal-regulating kinase 1
}

\author{
Y-C Cho ${ }^{1}$, JE Park ${ }^{2}$, BC Park ${ }^{2}$, J-H Kim ${ }^{3}$, DG Jeong ${ }^{2}$, SG Park ${ }^{\star 2}$ and S Cho ${ }^{\star, 1}$
}

Cdc25C (cell division cycle 25C) phosphatase triggers entry into mitosis in the cell cycle by dephosphorylating cyclin B-Cdk1. Cdc25C exhibits basal phosphatase activity during interphase and then becomes activated at the $G_{2} / M$ transition after hyperphosphorylation on multiple sites and dissociation from 14-3-3. Although the role of Cdc25C in mitosis has been extensively studied, its function in interphase remains elusive. Here, we show that during interphase Cdc25C suppresses apoptosis signal-regulating kinase 1 (ASK1), a member of mitogen-activated protein (MAP) kinase kinase kinase family that mediates apoptosis. Cdc25C phosphatase dephosphorylates phospho-Thr-838 in the activation loop of ASK1 in vitro and in interphase cells. In addition, knockdown of Cdc25C increases the activity of ASK1 and ASK1 downstream targets in interphase cells, and overexpression of Cdc25C inhibits ASK1-mediated apoptosis, suggesting that Cdc25C binds to and negatively regulates ASK1. Furthermore, we showed that ASK1 kinase activity correlated with Cdc25C activation during mitotic arrest and enhanced ASK1 activity in the presence of activated Cdc25C resulted from the weak association between ASK1 and Cdc25C. In cells synchronized in mitosis following nocodazole treatment, phosphorylation of Thr-838 in the activation loop of ASK1 increased. Compared with hypophosphorylated Cdc25C, which exhibited basal phosphatase activity in interphase, hyperphosphorylated Cdc25C exhibited enhanced phosphatase activity during mitotic arrest, but had significantly reduced affinity to ASK1, suggesting that enhanced ASK1 activity in mitosis was due to reduced binding of hyperphosphorylated Cdc25C to ASK1. These findings suggest that Cdc25C negatively regulates proapoptotic ASK1 in a cell cycle-dependent manner and may play a role in $G_{2} / M$ checkpointmediated apoptosis.

Cell Death and Differentiation (2015) 22, 1605-1617; doi:10.1038/cdd.2015.2; published online 30 January 2015

Cell division cycle 25 (Cdc25) phosphatases are dualspecificity phosphatases involved in cell cycle regulation. By removing inhibitory phosphate groups from phospho-Thr and phospho-Tyr residues of cyclin-dependent kinases (CDKs), ${ }^{1}$ Cdc25 proteins regulate cell cycle progression in $\mathrm{S}$ phase and mitosis. In mammals, three isoforms of Cdc25 phosphatases have been reported: Cdc25A, which controls the $G_{1} / S$ transition; ${ }^{2,3}$ Cdc25B, which is a mitotic starter; ${ }^{4}$ and Cdc25C, which controls the $\mathrm{G}_{2} / \mathrm{M}$ phase. ${ }^{5}$ Overexpression of Cdc25 phosphatases is frequently associated with various cancers. ${ }^{6}$ Upon exposure to DNA-damaging reagents like UV radiation or free oxygen radicals, Cdc25 phosphatases are key targets of the checkpoint machinery, resulting in cell cycle arrest and apoptosis. The 14-3-3 proteins bind to phosphorylated Ser216 of $\mathrm{Cdc} 25 \mathrm{C}$ and induce $\mathrm{Cdc} 25 \mathrm{C}$ export from the nucleus during interphase in response to DNA damage, ${ }^{7,8}$ but they have no apparent effect on Cdc25C phosphatase activity. 9 In addition, hyperphosphorylation of Cdc25C correlates to its enhanced phosphatase activity. ${ }^{11}$ Most studies with Cdc25C have focused on its role in mitotic progression. However, the role of Cdc25C is not clear when it is sequestered in the cytoplasm by binding to 14-3-3.

Apoptosis signal-regulating kinase 1 (ASK1), also known as mitogen-activated protein kinase kinase kinase 5 (MAPKKK5), is a ubiquitously expressed enzyme with a molecular weight of $170 \mathrm{kDa}$. The kinase activity of ASK1 is stimulated by various cellular stresses, such as $\mathrm{H}_{2} \mathrm{O}_{2},{ }^{12,13}$ tumor necrosis factor- $a$ (TNF-a), ${ }^{14}$ Fas ligand, ${ }^{15}$ serum withdrawal, ${ }^{13}$ and ER stress. ${ }^{16}$ Stimulated ASK1 phosphorylates and activates downstream MAP kinase kinases (MKKs) involved in c-Jun N-terminal kinase (JNK) and p38 pathways. ${ }^{17-19}$ Phosphorylation and activation of ASK1 can induce apoptosis, differentiation, or other cellular responses, depending on the cell type. ASK1 is regulated either positively or negatively depending on its binding proteins. ${ }^{12,13,15,18-25}$

ASK1 is regulated by phosphorylation at several Ser/Thr/Tyr residues. Phosphorylation at Thr-838 leads to activation of ASK1, whereas phosphorylation at Ser-83, Ser-967,

\footnotetext{
${ }^{1}$ College of Pharmacy, Chung-Ang University, Seoul 156-756, Republic of Korea; ${ }^{2}$ Medical Proteomics Research Center, Korea Research Institute of Bioscience and Biotechnology, Daejeon 305-806, Republic of Korea and ${ }^{3}$ Targeted Gene Regulation Research Center, Korea Research Institute of Bioscience and Biotechnology, Daejeon 305-333, Republic of Korea

*Corresponding author: SG Park, Medical Proteomics Research Center, Korea Research Institute of Bioscience and Biotechnology, Daejeon 305-806, Republic of Korea. Tel: +82 42860 4262; Fax: +82 42860 4269; E-mail: sgpark@ kribb.re.kr

or S Cho, College of Pharmacy, Chung-Ang University, 84 Heuksuk-Ro, DongJak-Gu, Seoul 156-756, Republic of Korea. Tel: +82 28205595 ; Fax: +82 28167338 ; E-mail: sycho@ cau.ac.kr

Abbreviations: ASK1, apoptosis signal-regulating kinase 1; Cdc25C, cell division cycle 25C; JNK, c-Jun N-terminal kinase; MAPK, mitogen-activated protein kinase; MKK, mitogen-activated protein kinase kinase; PARP, poly(ADP-ribose) polymerase; PTP, protein tyrosine phosphatase; TNF- $\alpha$, tumor necrosis factor- $\alpha$ Received 30.7.14; revised 16.10.14; accepted 17.11.14; Edited by M Deshmukh; published online 30.1.15
} 
or Ser-1034 inactivates ASK1. ${ }^{24,26-28}$ ASK1 is basally phosphorylated at Ser-967 by an unidentified kinase, and 14-3-3 binds to this site to inhibit ASK1 ${ }^{24}$ Phosphorylation at Ser-83 is known to be catalyzed by Akt or PIM1.27,29 Oligomerization-dependent autophosphorylation at Thr-838, which is located in the activation loop of the kinase domain, is essential for ASK1 activation. ${ }^{14,18,30}$ Phosphorylation at Tyr-718 by JAK2 induces ASK1 degradation. ${ }^{31}$ Several phosphatases that dephosphorylate some of these sites have been identified. Serine/threonine protein phosphatase type 5 (PP5) and PP2C dephosphorylate phosphorylated ( $p)$-Thr-838, ${ }^{28,32}$ whereas PP2A and SHP2 dephosphorylate p-Ser-967 and p-Tyr-718, respectively. ${ }^{31,33}$ Little is known about the kinase or phosphatase that regulates phosphorylation at Ser-1034. Although ASK1 phosphorylation is known to be involved in the regulation of apoptosis, only a few reports show that ASK1 phosphorylation or activity is dependent on the cell cycle. ${ }^{21,34}$

In this study, we examined the functional relationship between Cdc25C and ASK1 and identified a novel function of Cdc25C phosphatase that can dephosphorylate and inhibit ASK1 in interphase but not in mitosis. Furthermore, we demonstrated that Cdc25C phosphorylation status plays a critical role in the interaction with and the activity of ASK1. These results reveal a novel regulatory function of Cdc25C in the ASK1-mediated apoptosis signaling pathway.

\section{Results}

Synchronization in mitosis with nocodazole treatment activates ASK1 signaling by modulating ASK1 phosphorylation. Our previous results and another report suggest that ASK1 activity is regulated during the cell cycle. The release of serum-starved HEK 293 cells into S phase or cell cycle arrest at the $\mathrm{G}_{2} / \mathrm{M}$ phase in MCF-7 (human breast adenocarcinoma) cells enhanced ASK1 activity without affecting ASK1 protein expression level. ${ }^{21,34}$ In order to investigate how ASK1 is regulated during mitosis, we used nocodazole, an antineoplastic agent that interferes with microtubule polymerization, to synchronize cells in prometaphase of mitosis. Both MCF-7 and HEK 293 cells were successfully synchronized in mitosis after $16 \mathrm{~h}$ of nocodazole treatment (Figure 1a). As autophosphorylation of ASK1 is essential for ASK1 kinase activity, we performed autophosphorylation assays to test whether ASK1 autophosphorylation is affected by nocodazole treatment (Figure 1b). ASK1 autophosphorylation levels in MCF-7 cells increased with increasing nocodazole incubation time, suggesting that ASK1 becomes more active at the $\mathrm{M}$ phase.

We then measured ASK1 phosphorylation status using antibodies specific to p-Ser-83, p-Thr-838, or p-Ser-967 of ASK1. As commercially available phospho-ASK1 antibodies specific to $p$-Ser-83, p-Thr-838, or p-Ser-967 of ASK1 detect transfected ASK1 only when those residues are phosphorylated, we first established a HEK 293 cell-based cell line that constitutively expressed FLAG-ASK1. No abnormality of cell growth or morphology was recognized for FLAG-ASK1expressing cells, hereafter called HEK 293-A1 cells. When ASK1 phosphorylation status in HEK 293-A1 cells was measured using antibodies specific to ASK1 p-Ser-83, p-Thr838, or $p$-Ser-967, $p$-Thr-838 levels were increased, but phosphorylation levels of ASK1 Ser-83 and Ser-967 were decreased with nocodazole treatment (Figure 1c). As phosphorylation at Ser-83 or Ser-967 inhibits ASK1 and phosphorylation at Thr-838 activates ASK1, our results suggest that ASK1 is activated when cells are synchronized in mitosis. To verify ASK1 activation after nocodazole treatment, we examined whether the phosphorylation levels of proteins downstream of ASK1 were affected. ASK1 activates p38 and JNK through phosphorylation of MKK3/ MKK6 and MKK4/MKK7, respectively, under various cellular stresses. ${ }^{35}$ As shown in Figure 1d, phosphorylation of p38, JNK, MKK7, and MKK4 increased in both nocodazoletreated MCF-7 and HEK 293-A1 cells. When synchronized cells were released into the cell cycle upon removal of nocodazole, the levels of $p$-Ser-83 and p-Ser-967 increased for $8 \mathrm{~h}$, whereas the level of $\mathrm{p}$-Thr-838 decreased, suggesting that the phosphorylation status of these sites depends on the cell cycle (Figure 1e).

Cdc25C interacts with and inhibits ASK1 in asynchronous HEK 293 cells. As the ASK1 phosphorylation state depends on the cell cycle, a cell cycle-dependent phosphatase might regulate ASK1 phosphorylation. In addition, ASK1 is regulated by phosphorylation at Ser/Thr or Tyr residues and many protein tyrosine phosphatases (PTPs) can act on Ser/Thr or Tyr residues. Therefore, we performed in vitro binding assays with ASK1 and 46 human PTPs from the 81 protein-targeting PTPs found in the human genome to identify possible ASK1-regulating phosphatases. ${ }^{22,36} \mathrm{We}$ repeated in vitro binding assays at least three times and found that Cdc25C interacted with ASK1 in all experiments.

As $\mathrm{Cdc} 25 \mathrm{C}$ is involved in the $\mathrm{G}_{2} / \mathrm{M}$-phase transition during the cell cycle, we further investigated how Cdc25C is involved in ASK1 regulation. We confirmed the endogenous association between ASK1 and Cdc25C proteins in asynchronous and untransfected HEK 293 cells (Figures 2a and b).

When we first examined whether ASK1 regulates Cdc25C stability or Ser-216 phosphorylation, neither the stability nor Ser-216 phosphorylation of Cdc25C were affected by ASK1 expression levels (Supplementary Figure S1). We then examined whether Cdc25C phosphatase regulates ASK1 activity. HEK 293 cells were cotransfected with FLAG-ASK1 and wild-type (WT) or catalytically inactive C377S mutant HACdc25C expression plasmids, and immunoprecipitation was performed using anti-FLAG M2 agarose. The immunoprecipitates were incubated with $\left[\gamma^{-32} \mathrm{P}\right]$-ATP in kinase reaction buffer, and ASK1 autophosphorylation levels were determined (Figure 2c). Autophosphorylation of ASK1 decreased in a Cdc25C dose-dependent manner, but it was not affected by the Cdc25C C377S mutant. We also determined ASK1 activity in cells transfected with small interfering RNAs targeting Cdc25C (Cdc25C siRNAs) to further confirm whether ASK1 kinase activity increases in Cdc25C-knockdown cells (Figure 2d). Cells transfected with Cdc25C siRNAs showed reduced levels of Cdc25C, whereas the ASK1 expression levels were not affected. In vitro kinase assays showed that Cdc25C knockdown also increased ASK1 autophosphorylation and phosphorylation of MKK6, a downstream factor of 
a

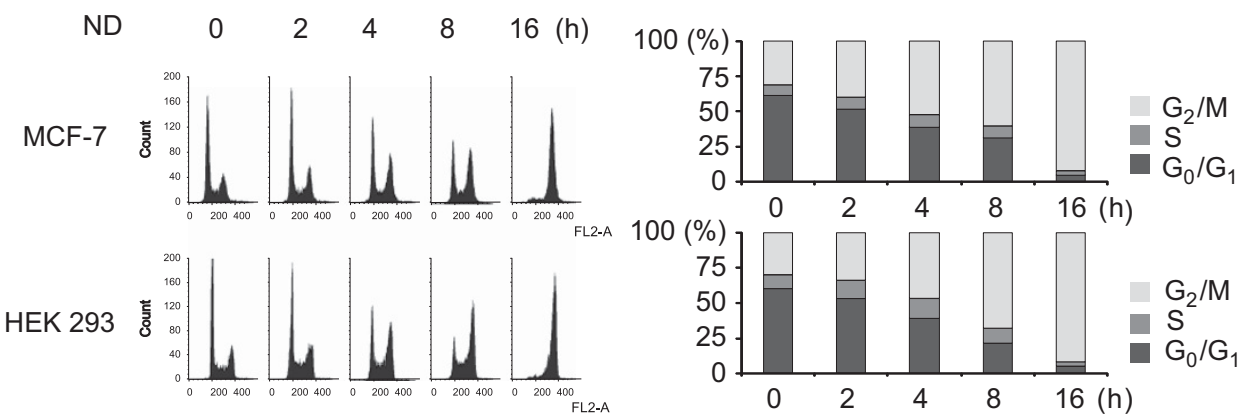

b

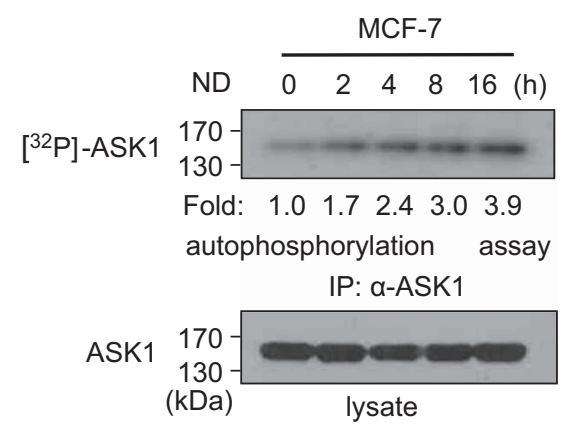

d

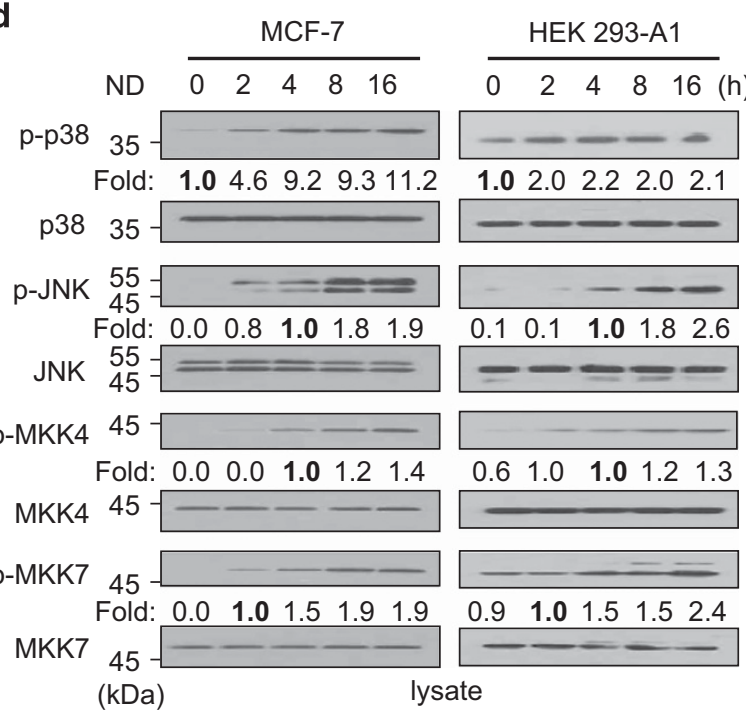

C

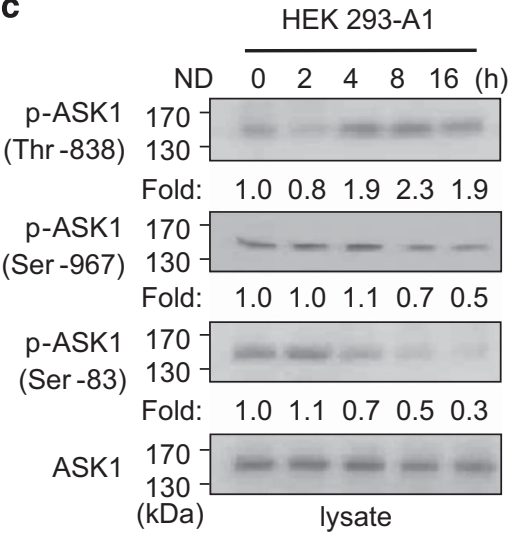

e

HEK 293-A1

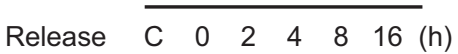

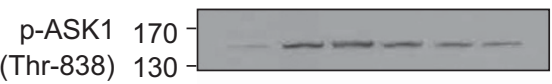

Fold: $\begin{array}{llllll}1.0 & 3.7 & 3.6 & 2.5 & 2.0 & 1.5\end{array}$

\begin{tabular}{rr|lllll} 
p-ASK1 & $170-$ & & & & & \\
(Ser-967) & $130-$ & & \\
& Fold: 1.0 & 0.2 & 0.3 & 0.7 & 0.9 & 1.2
\end{tabular}

$\begin{array}{ll}\text { p-ASK1 } & 170-\square-\longrightarrow-\square \\ \text { (Ser-83) } & 130--\square\end{array}$

Fold: $\begin{array}{llllll}1.0 & 0.2 & 0.2 & 0.5 & 0.7 & 0.9\end{array}$

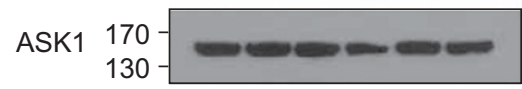

(kDa) lysate

Figure 1 Synchronization by nocodazole activates ASK1/MAPK signaling in MCF-7 and HEK 293 cells. (a) Nocodazole induced cell cycle synchronization at the mitotic phase. MCF-7 cells or HEK 293 cells were treated with nocodazole $(200 \mathrm{ng} / \mathrm{ml})$ for the indicated time points $(0,2,4,8$, or $16 \mathrm{~h})$. Cell cycle distributions were determined by fluorescence-activated cell sorting (FACS). Quantitative analyses of the FACS data are shown in the right panel. ND, nocodazole. (b) Nocodazole induced activation of ASK1. MCF-7 cell lysates were immunoprecipitated with an anti-ASK1 antibody, and ASK1 activities were determined using autophosphorylation assays. Protein phosphorylation levels were quantified by scanning the autoradiographs, followed by analysis with LabWorks software (UVP, Upland, CA, USA). (c and d) Nocodazole enhanced the activation of ASK1/ MAPK signaling. Cells were treated with nocodazole $(200 \mathrm{ng} / \mathrm{ml})$ for the indicated time points, and protein phosphorylation levels or expression levels were assessed by immunoblot analysis as described in Materials and Methods. Those levels were quantified by analysis with LabWorks software and normalized to corresponding unphosphorylated protein levels. (e) Release of synchronized cells into $\mathrm{G}_{1} / \mathrm{S}$ phase reversed phospho-ASK1 levels. HEK 293-A1 cells were exposed to nocodazole (200 ng/ml) for $16 \mathrm{~h}$, subsequently released into fresh media, and harvested at the indicated time points. Cell lysates containing equal amounts of protein were analyzed by SDS-PAGE and immunoblotted with appropriate antibodies. Protein phosphorylation levels were quantified by scanning the immunoblots and analyzing them with LabWorks software. The control lane (C) shows data obtained from asynchronous cells

ASK1. Taken together, the results show that Cdc25C negatively regulates ASK1 activity.

Cdc25C dephosphorylates p-Thr-838 of ASK1. As ASK1 activity is dependent on Cdc25C expression level, we investigated whether ASK1 is dephosphorylated by Cdc25C. In this study, $\mathrm{H}_{2} \mathrm{O}_{2}$ or TNF- $a$, which may induce degradation or inactivation of $\mathrm{Cdc} 25 \mathrm{C},{ }^{37}$ was used to induce ASK1 phosphorylation on Thr-838 in cells. Therefore, we first tested whether $\mathrm{H}_{2} \mathrm{O}_{2}$ or TNF- $a$ treatment could interfere with 


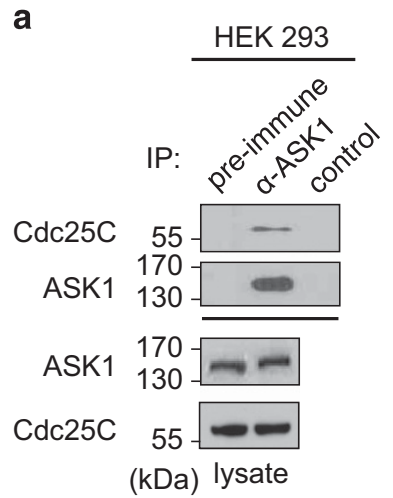

C

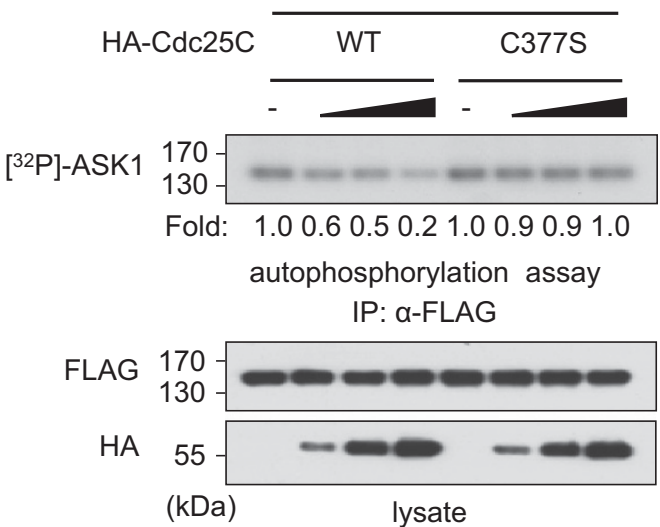

b

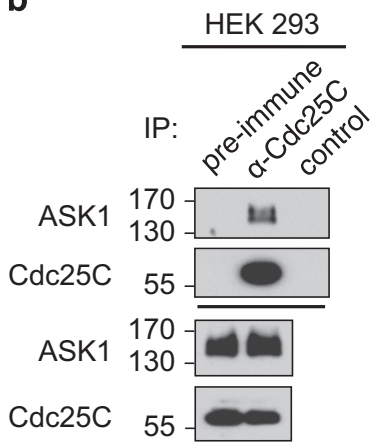

(kDa) lysate

d
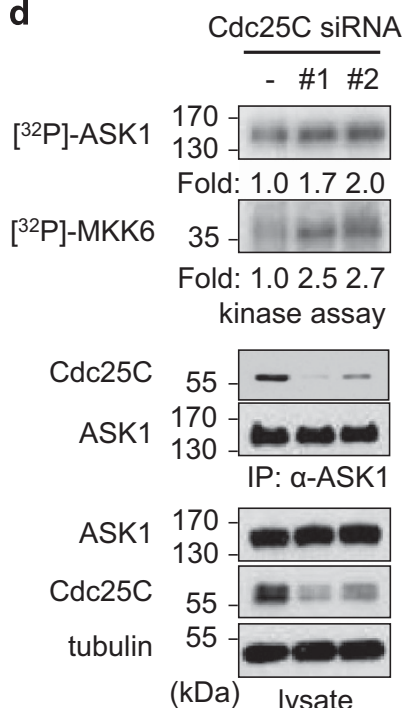

Figure 2 Endogenous Cdc25C-mediated interaction and regulation of ASK1 in asynchronous HEK 293 cells. (a) Interaction between endogenous ASK1 and Cdc25C proteins. Cell lysates from untransfected HEK 293 cells were immunoprecipitated with rabbit preimmune serum or anti-ASK1, as described in Materials and Methods. The immunoprecipitates were analyzed by SDS-PAGE and immunoblotted with an anti-Cdc25C or anti-ASK1 antibody. The far right lane (control) shows an immunoblot of anti-ASK1 antibody plus protein $A / G$ agarose used in the immunoprecipitation to confirm no indigenous IgG reactivity. The levels of endogenous proteins were measured using the appropriate antibodies, as indicated. ASK1, apoptosis signal-regulating kinase 1; Cdc25C, cell division cycle 25 C; $\lg G$, immunoglobulin G; SDS-PAGE, sodium dodecyl sulfatepolyacrylamide gel electrophoresis; IP, immunoprecipitation. (b) HEK 293 cell lysates were immunoprecipitated with rabbit preimmune serum or anti-Cdc25C antibody and then analyzed by SDS-PAGE and immunoblot analysis with an anti-ASK1 or anti-Cdc25C antibody. The far right lane (control) shows immunoblotting of an anti-Cdc25C antibody and the protein $\mathrm{A} / \mathrm{G}$ agarose used in the immunoprecipitation. The levels of endogenous proteins were measured using the appropriate antibodies, as indicated. (c) Inactivation of ASK1 by Cdc25C in asynchronous cells. HEK 293 cells were cotransfected with FLAG-ASK1 and various amounts (0.5, 1, or $2 \mu \mathrm{g})$ of HA-Cdc25C (WT or C377S) expression plasmids. After $48 \mathrm{~h}$ of transfection, cell lysates were immunoprecipitated with anti-FLAG M2 agarose, and after extensive washing to remove associated endogenous Cdc25C, the immunoprecipitates were analyzed for ASK1 kinase activity by autophosphorylation assay. The expression levels of Cdc25C and ASK1 were determined by immunoblotting with anti-HA and anti-FLAG antibodies, respectively. (d) The effect of Cdc25C knockdown on ASK1 activation was determined. HEK 293 cells were transfected with $1 \mu \mathrm{g}$ of scrambled siRNA or Cdc25C siRNAs (\#1: 5'-CUACUUUCUCUCCUCUUGU-3' (dTdT), \#2: 5'-CCUGAAAGAUCAAGAAGCA-3' (dTdT)). After 48 h of transfection, cell lysates were immunoprecipitated with anti-ASK1 agarose and analyzed for autophosphorylation and in vitro kinase activities of ASK1. In vitro kinase assays were performed using His-MKK6 as a substrate. Kinase activity was normalized to the expression level of ASK1

Cdc25C phosphatase activity or stability in our experimental conditions. Results showed that neither $\mathrm{H}_{2} \mathrm{O}_{2}$ nor TNF-a used had effect on Cdc25C activity or expression (Figure 3a).

We then examined which phosphorylated residues of ASK1 were dephosphorylated by Cdc25C phosphatase in vitro. For in vitro phosphatase assays, the His-tagged catalytic domain (residues 207-400) of Cdc25C was expressed in and purified from bacteria because expression levels of full-length Cdc25C in bacteria were not high enough for purification. Before in vitro phosphatase assays, the interaction between ASK1 and the recombinant His-Cdc25C catalytic domain was confirmed. After transfection with FLAG-ASK1 plasmid, $\mathrm{H}_{2} \mathrm{O}_{2}$-treated
HEK 293 cells were prepared, and the lysates were immunoprecipitated using anti-FLAG M2 agarose. When immunoprecipitated ASK1 was incubated with the recombinant His-Cdc25C catalytic domain, ASK1 interacted with recombinant $\mathrm{Cdc} 25 \mathrm{C}$ in vitro (Figure $3 \mathrm{~b}$ ). Then, recombinant His-Cdc25C and immunoprecipitated ASK1 were used for in vitro phosphatase assays, followed by immunoblot analysis with anti-phospho-ASK1 Thr-838, Ser-967, or Ser-83 antibody (Figure 3c). Immunoblot analysis showed that phosphorylation of ASK1 Thr-838 was clearly reduced, but phosphorylation of other sites was not affected by Cdc25C. In addition, the catalytically active recombinant Cdc25C WT significantly 
a

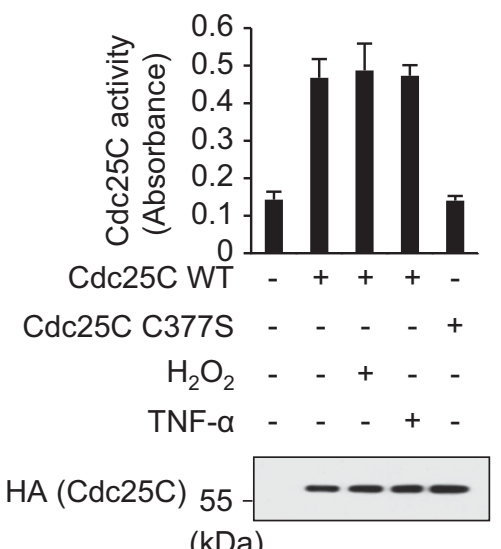

b

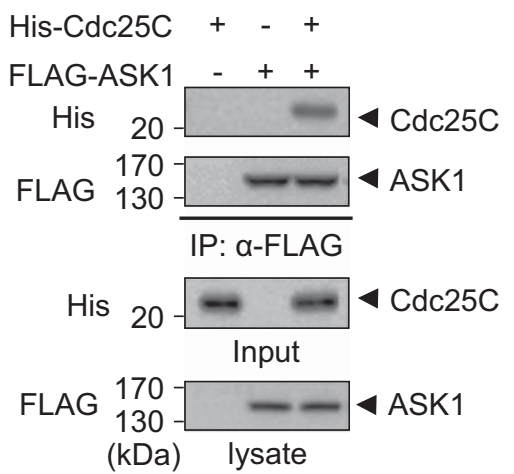

C

p-ASK1 170

(Thr-838) 130

Fold: 1.00 .21 .1

$\begin{array}{rrr}\text { p-ASK1 } 170- \\ \text { (Ser-967) } & 130--\cdots\end{array}$

Fold: 1.01 .11 .1

p-ASK1 170

(Ser-83) $130--\cdots$

Fold: 1.00 .90 .9

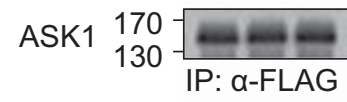

His $20-\quad--$ d

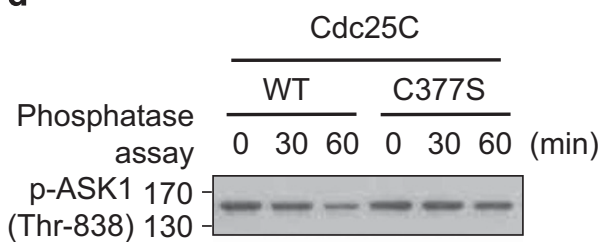

Fold: 1.00 .80 .31 .01 .00 .9

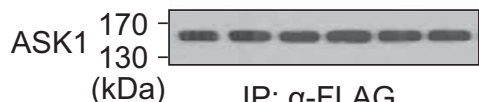

e

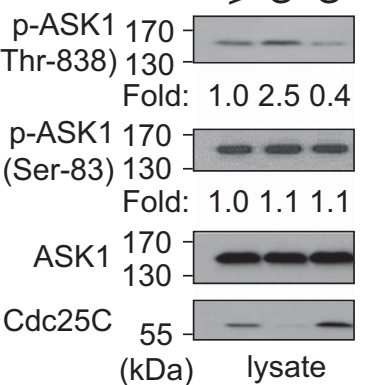

Figure 3 Cdc25C inactivates ASK1 kinase activity by dephosphorylating p-Thr-838 of ASK1. (a) The effect of $\mathrm{H}_{2} \mathrm{O}_{2}$ or TNF- $\alpha$ on Cdc25C phosphatase activity in cells was measured. HEK 293 cells were transiently transfected with HA-Cdc25C WT or C377S mutant expression plasmids, and then lysates from cells that were either untreated or treated with $\mathrm{H}_{2} \mathrm{O}_{2}(1 \mathrm{mM})$ or TNF- $\alpha(20 \mathrm{ng} / \mathrm{ml})$ for $1 \mathrm{~h}$ were immunoprecipitated with anti-HA affinity agarose. The immunoprecipitates were incubated with OMFP to measure phosphatase activity. Data represent the mean \pm S.E.M. of six observations from three independent experiments. (b) The catalytic domain of Cdc25C (residues 207-400), purified from bacteria, was used to test interaction with ASK1. HEK 293 cells after transfection with empty or FLAG-ASK1 expression plasmids were treated with 1 mM $\mathrm{H}_{2} \mathrm{O}_{2}$ for $30 \mathrm{~min}$ to phosphorylate Thr-838, and then cell lysates were incubated with anti-FLAG M2 agarose at $4^{\circ} \mathrm{C}$ for $4 \mathrm{~h}$. After incubation, the anti-FLAG M2 agarose was washed extensively and then incubated at $4^{\circ} \mathrm{C}$ for $3 \mathrm{~h}$ with or without purified recombinant His-Cdc25C (residues 207-400). After extensive washing of the anti-FLAG M2 agarose, complexes were analyzed by immunoblot with anti-His antibody. (c) Phosphorylation sites of ASK1 were evaluated after treatment with Cdc25C in vitro. HEK 293-A1 cells were treated with $1 \mathrm{mM} \mathrm{H}_{2} \mathrm{O}_{2}$ for $30 \mathrm{~min}$, and then cell lysates were immunoprecipitated with anti-FLAG M2 agarose and incubated with $0.5 \mu \mathrm{g}$ of purified recombinant His-Cdc25C WT or C377S mutant proteins (residues $207-400$ ) at $30^{\circ} \mathrm{C}$ for $60 \mathrm{~min}$. The effects of Cdc25C on ASK1 dephosphorylation were confirmed by immunoblot analysis. Relative phosphorylation levels of ASK1 compared with control (nontreated sample) were quantified by scanning the immunoblots and analyzing them with LabWorks software. (d) Dephosphorylation of ASK1 Thr-838 was evaluated after treatment with Cdc25C in vitro. Immunoprecipitates from HEK 293-A1 cell lysates were incubated with recombinant His-Cdc25C WT or C377S mutant proteins (residues 207-400) for the indicated times as described in (c). The effects of Cdc25C on ASK1 dephosphorylation were confirmed by immunoblot analysis. (e) The effects of Cdc25C expression levels on Thr-838 phosphorylation of ASK1 were determined. Asynchronous HEK 293-A1 cells were transfected with empty vector, Cdc25C siRNA\#1, or HA-Cdc25C WT plasmid. After $48 \mathrm{~h}$ of transfection, cells were lysed with PTP lysis buffer. Cell lysates were subjected to immunoblot using anti-Cdc25C, anti-ASK1, and anti-phospho-ASK1 (Ser-83 or Thr-838) antibodies

reduced the p-Thr-838 level in ASK1 in a time-dependent manner, whereas the phosphatase-inactive Cdc25C C377S mutant failed to dephosphorylate $\mathrm{p}$-Thr-838 (Figures $3 \mathrm{c}$ and d). These results indicate that Cdc25C directly and specifically dephosphorylates $\mathrm{p}$-Thr-838 of ASK1.

To further investigate whether Cdc25C expression in asynchronous cells could affect phosphorylation on Thr-838 of ASK1, HEK 293-A1 cells were transfected with Cdc25C siRNA, Cdc25C WT, or empty vector. Cell lysates were analyzed by SDS-PAGE followed by immunoblot with appropriate anti-ASK1 or anti-Cdc25C antibodies (Figure 3e). Cells transfected with Cdc25C siRNA had increased ASK1 p-Thr-838 levels, but cells overexpressing Cdc25C WT had reduced p-Thr-838. In contrast, the ASK1 p-Ser-83 levels were 
not affected by Cdc25C. Collectively, these data suggest that Cdc25C specifically dephosphorylates ASK1 p-Thr-838 both in vitro and in cells.

Cdc25C inhibits ASK1-mediated apoptosis in asynchronous cells. We next examined whether Cdc25C regulates ASK1-mediated apoptosis. After asynchronous MEF cells were transfected with ASK1 and Cdc25C expression plasmids, cells were treated with $\mathrm{H}_{2} \mathrm{O}_{2}$ and used for cell viability assays and immunoblot analyses (Figure 4a). When ASK1 was overexpressed, $\sim 40 \%$ of cells died. However, when Cdc25C was coexpressed along with ASK1, $\mathrm{H}_{2} \mathrm{O}_{2}$ treated cells exhibited increased cell viability compared with those expressing ASK1 alone. Taken together, our results suggest that ASK1 proapoptotic activity is inhibited by Cdc25C in asynchronous cells.

As ASK1 is a key regulator of caspase-3-dependent apoptosis, we examined the role of Cdc25C in apoptosis by a

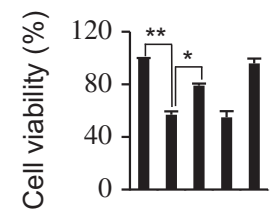

ASK1 WT - + + + -

ASK1 T838A - . - +

Cdc25C WT - - + - -

Cdc25C C377S - - + +

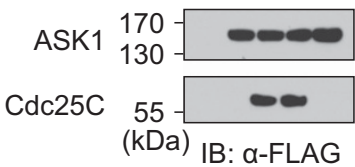

C

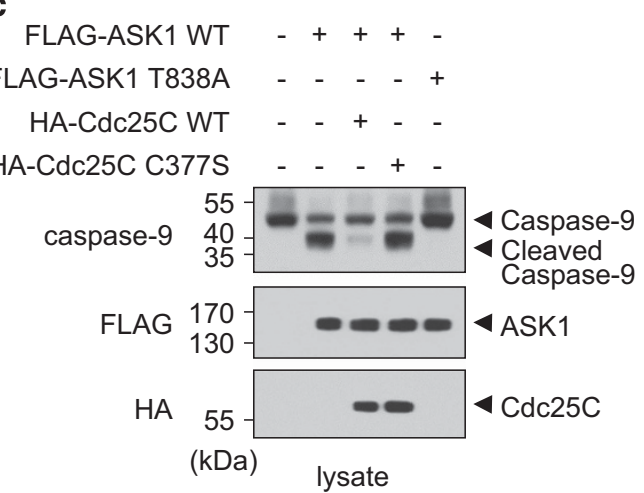

b

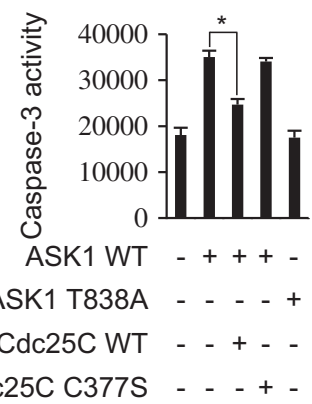

d
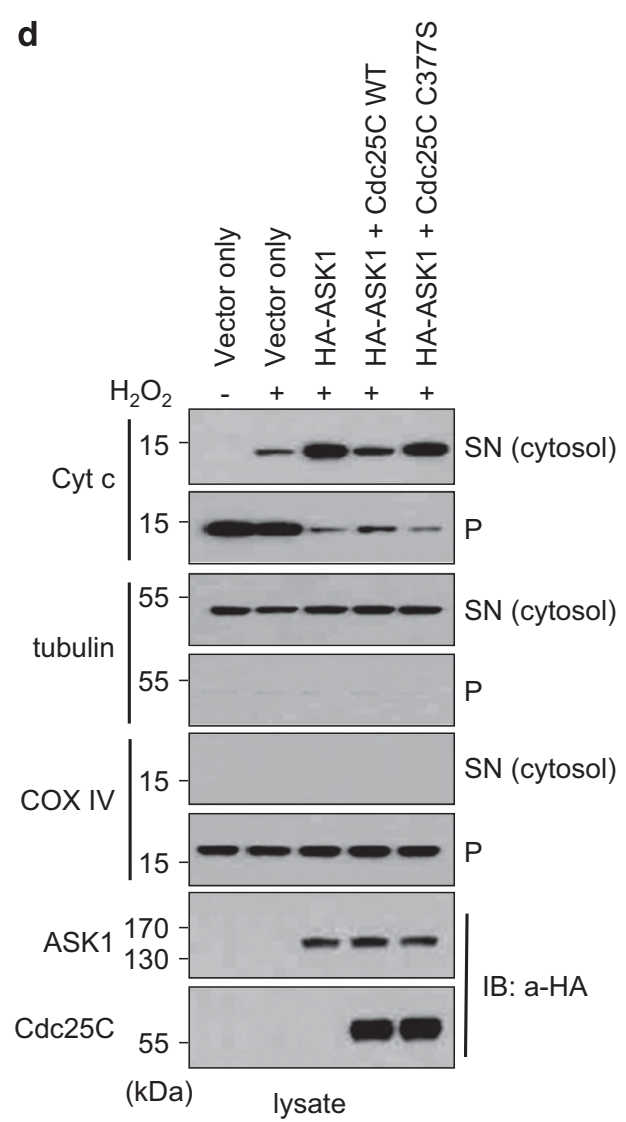

Figure 4 Cdc25C reduces ASK1-mediated apoptosis, dependent on the phosphatase activity. (a) Cell viability was determined as described in Materials and Methods. MEF cells were transfected with FLAG-ASK1 (WTor T838A mutant, $1 \mu \mathrm{g}$ ) or FLAG-Cdc25C (WTor C377S mutant, $1 \mu \mathrm{g}$ ) expression plasmid. Data represent the mean \pm S.E.M. of six observations from three independent experiments. The kinase-inactive ASK1 T838A mutant was used as a control. The expression levels of Cdc25C and ASK1 were determined by immunoblotting with an anti-FLAG antibody. IB, immunoblot. ${ }^{*} P<0.01$ and ${ }^{*} P<0.05$ versus the control sample by Student's $t$-test. (b) The effect of Cdc25C on caspase-3 activity in MEF cells was determined. After $48 \mathrm{~h}$ of transfection, cells were treated with $1 \mathrm{mM} \mathrm{H}_{2} \mathrm{O}_{2}$ for $4 \mathrm{~h}$. Cells were lysed, and the caspase-3 activities in lysates were measured using DEVD-7-amino-4-methylcoumarin as a substrate. Graphs represent the mean of three independent experiments. Error bars indicate the S.E.M. ${ }^{*} P<0.05$ versus the control sample by Student's $t$-test. (c) The effect of Cdc25C on caspase-9 processing was determined. After transfection, MEF cells were lysed and immunoblotted with an anti-caspase9 antibody. (d) The release of cytochrome $c$ into the cytosol of transfected MEF cells was determined by immunoblot analysis after separation of cytosol (SN) from cell precipitate (P). The presence of tubulin, a cytosolic marker, and COX IV, a mitochondrial marker, in each fraction was revealed by immunoblot. Cyt $c$, cytochrome $c$; P, pellet; SN, supernatant 
measuring the caspase-3 activity using DEVD-7-amino4-methylcoumarin as a caspase-3 substrate (Figure 4b). Exogenous expression of Cdc25C inhibited ASK1-mediated caspase-3 activity, but phosphatase-inactive Cdc25C C377S did not inhibit caspase-3 activity. In addition, the kinaseinactive ASK1 T838A mutant did not induce caspase-3 activity. The inhibitory role of Cdc25C in ASK1-mediated apoptosis was further confirmed by measuring levels of active cleaved caspase-9, an apoptotic initiator, by immunoblot (Figure 4c). Induction of active cleaved caspase-9 was suppressed when Cdc25C WT was coexpressed, but the Cdc25C C377S mutant failed to suppress caspase-9 cleavage. As ASK1 activation induces cytochrome $c$ release from mitochondria as well as activation of caspase-9 and caspase- $3,{ }^{38}$ we tested and confirmed that ASK1-induced cytochrome $c$ release from mitochondria into the cytosol was significantly reduced in the presence of Cdc25C WT but not in the presence of Cdc25C C377S (Figure 4d).

Nocodazole treatment results in changes in Cdc25C phosphorylation status and ASK1-mediated apoptosis. Phosphorylation of Cdc25C at Ser-216 renders a binding site for the 14-3-3 proteins, which are required for checkpoint arrest, causing Cdc25C nuclear export. ${ }^{8}$ In addition, Cdc25C is hyperphosphorylated at the $\mathrm{G}_{2} / \mathrm{M}$ transition through phosphorylation at multiple sites, with the exception of Ser-216, and exhibits high phosphatase activity. ${ }^{39}$ To more precisely assess the status of Cdc25C in nocodazole-treated cells, we evaluated gene expression, Ser-216 phosphorylation, and protein migration patterns by SDS-PAGE. Expression levels of Cdc25C mRNA in both MCF-7 and HEK 293 cells did not change upon exposure to nocodazole as judged by semiquantitative reverse transcription-PCR (RT-PCR; Figure 5a). However, immunoblotting with an anti-Cdc25C antibody after electrophoresis on SDS-PAGE gels with cell lysates from nocodazole-treated HEK 293-A1 or HEK 293 cells revealed slower migrating Cdc25C, suggesting hyperphosphorylation of Cdc25C protein as reported previously (Figure $5 \mathrm{~b}$ and Supplementary Figure S2a). ${ }^{40}$ Treatment of cell lysates from nocodazole-treated HEK 293 cells with calf intestine phosphatase (CIP), a nonspecific phosphatase for the phosphorylated Tyr and Ser/Thr residues, resulted in a faster migrating $\mathrm{Cdc} 25 \mathrm{C}$ protein band, confirming that the slower migrating Cdc25C is hyperphosphorylated (Supplementary Figure S2b). Furthermore, the increase in hyperphosphorylated Cdc25C in nocodazole-treated cells was accompanied by a reduction in Cdc25C p-Ser-216, leading to 14-3-3 binding and Cdc25C nuclear export (Figure 5b and Supplementary Figure S2a). When nocodazole-treated HEK 293-A1 cells were released into cell cycle progression upon removal of nocodazole, hyperphosphorylated Cdc25C decreased with release time, and Ser-216 phosphorylation levels increased accordingly (Figure $5 c$ and Supplementary Figure S2c). These results confirmed previous reports that Cdc25C is hyperphosphorylated, with Ser-216 being dephosphorylated, in nocodazole-treated cells. ${ }^{40}$ We then examined whether ASK1 suppression after release from mitotic arrest (as shown in Figure 1e) was reversed in Cdc25C-knockdown cells. When nocodazole-treated Cdc25C-knockdown HEK 293-A1 cells were released from nocodazole arrest upon addition of fresh medium, phosphorylation levels of ASK1 Thr-838 increased independently of nocodazole removal time (Figure $5 \mathrm{~d}$ ), suggesting that ASK1 Thr-838 phosphorylation is dependent on Cdc25C, but not on nocodazole.

As long nocodazole exposures induce apoptosis as well as synchronization in mitosis in cells, ${ }^{41}$ we examined a possible linkage between nocodazole-induced apoptosis and ASK1 by measuring the processing of procaspase-3 and cleavage of poly(ADP-ribose) polymerase (PARP), the major substrate of caspase-3, in nocodazole-treated $A S K 1^{-/-}$cells (Figure 5e). After treatment with nocodazole, $A S K 1^{-1-}$ cells displayed reduced caspase-3 processing and PARP cleavage compared with ASK1 WT cells. Taken together, the results suggest that ASK1 is involved in nocodazole-induced apoptosis.

Phosphorylation status of Cdc25C changes binding affinity to ASK1 in mitotic cells. Given that treatment with nocodazole induces hyperphosphorylation and activation of Cdc25C in cells ${ }^{39,40}$ in addition to enhancement of ASK1 kinase activity, the relationship between Cdc25C hyperphosphorylation and ASK1 Thr-838 phosphorylation was investigated after treatment with small molecules such as paclitaxel and dolastatin 15 that disrupt microtubule or actin polymerization, respectively (Figure 6a). When the levels of hyperphosphorylated Cdc25C were high, high p-Thr-838 ASK1 levels were also detected. However, monastrol, which does not induce Cdc25C hyperphosphorylation but synchronizes cells in mitosis by inhibiting the kinesin Eg5, a motor protein important for spindle bipolarity, failed to increase pThr-838 ASK1 levels (Figure 6a), suggesting that phosphorylation of ASK1 Thr-838 correlates with Cdc25C hyperphosphorylation. Hyperphosphorylation of Cdc25C was still detected in nocodazole-treated $A S K 1^{-/-}$cells, suggesting that ASK1 is not involved in the hyperphosphorylation of Cdc25C (Supplementary Figure S3).

To further determine whether Cdc25C hyperphosphorylation indeed affects ASK1 Thr-838 phosphorylation under more physiological conditions, HEK 293-A1 cells were synchronized in $S$ phase using a double thymidine block. Synchronized HEK 293-A1 cells were released upon removal of the double thymidine block. Cell lysates were prepared from cells collected after release for the indicated time points and used for immunoblot analysis. As shown in Supplementary Figure $S 4$, cells were enriched in the $G_{2} / M$ phase after release to normal cell cycle for 6 and $8 \mathrm{~h}$. In accordance with the FACS data, Cdc25C hyperphosphorylation increased at 6, 8, and $10 \mathrm{~h}$ after release, and ASK1 Thr-838 phosphorylation increased in a similar manner (Figure 6b).

As ASK1 is activated in the presence of hyperphosphorylated Cdc25C and phosphorylation of Ser-83 or Ser-967 results in inhibition of ASK1 kinase activity, we expected that hyperphosphorylated Cdc25C might dephosphorylate either p-Ser-83 or p-Ser-967 rather than p-Thr-838 of ASK1. However, dephosphorylation of $\mathrm{p}$-Ser-83 or $\mathrm{p}-\mathrm{Ser}-967$ was not mediated by Cdc25C (Figures 3c and e), whereas ASK1 Thr-838 was phosphorylated in nocodazole-treated cells, as shown in Figure 1c. Therefore, we sought to elucidate how ASK1 could be activated in the presence of hyperphosphorylated Cdc25C in cells synchronized in mitosis. Differential subcellular localization of these two proteins was 
a

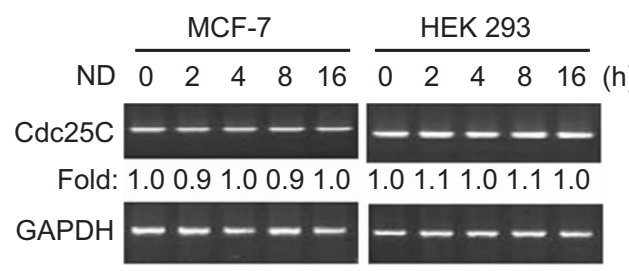

C

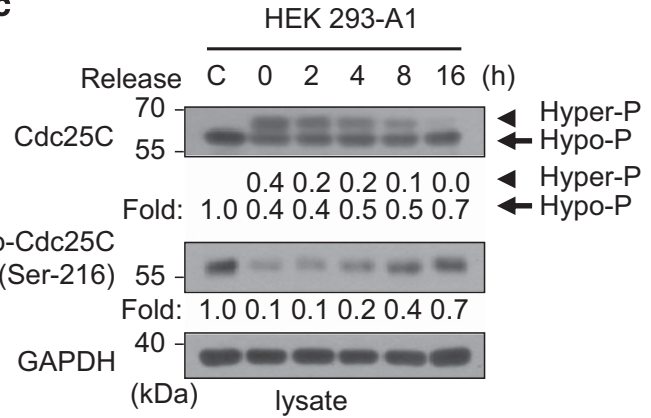

b

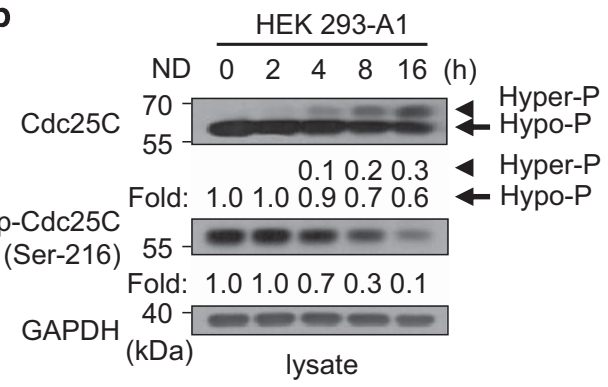

d

Cdc25C siRNA \#1

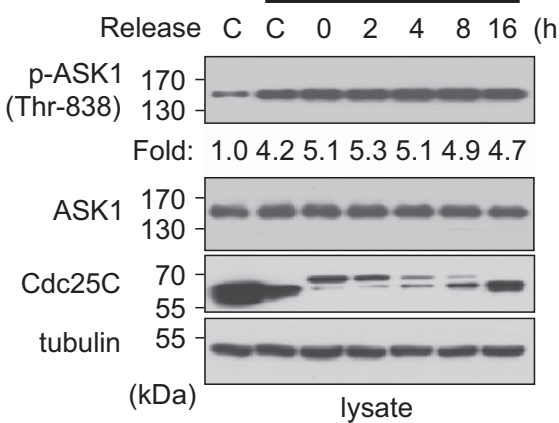

e

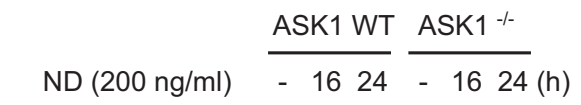

cleaved PARP

100

Fold: 0.01 .00 .70 .00 .60 .3

cleaved caspase-3 15

Fold: 0.11 .00 .70 .10 .30 .2

ASK1 170

GAPDH $\begin{gathered}40-\square \\ (\mathrm{kDa})\end{gathered}$

lysate

Figure 5 Nocodazole treatment results in changes in Cdc25C phosphorylation status and ASK1-mediated apoptosis, but it is not required for ASK1 activation. (a) Expression of the Cdc25C gene was determined at 0, 2, 4, 8, and $16 \mathrm{~h}$ in MCF-7 or HEK 293 cells after $200 \mathrm{ng} / \mathrm{ml}$ nocodazole treatment. An anti-GAPDH antibody was used as a loading control for immunoblotting. (b) The effect of nocodazole on hyperphosphorylation and Ser-216 phosphorylation of Cdc25C was determined. HEK 293-A1 cells were treated with nocodazole $(200 \mathrm{ng} / \mathrm{ml})$ for the indicated times, and the lysates were assessed by immunoblot analysis with anti-Cdc25C or anti-p-Cdc25C (Ser-216) antibody. An anti-GAPDH antibody was used as a loading control for immunoblotting. (c) Changes in p-Ser-216 or hyperphospho-Cdc25C after removal of nocodazole were determined. HEK 293-A1 cells were exposed to nocodazole (200 ng/ml) for $16 \mathrm{~h}$, subsequently released into fresh media, and harvested at the indicated time points. Cell lysates containing equal amounts of protein were separated by SDS-PAGE and immunoblotted with an anti-Cdc25C, anti-p-Cdc25C (Ser-216), or anti-GAPDH antibody. Protein levels were analyzed by immunoblot and quantified by scanning the immunoblots followed by analysis with LabWorks software. The far left lane $(\mathrm{C})$ shows data obtained from unexposed asynchronous cells. (d) HEK 293-A1 cells were transfected with $1 \mu \mathrm{g}$ of Cdc25C siRNA\#1. After $48 \mathrm{~h}$ of transfection, cells were exposed to nocodazole (200 $\mathrm{ng} / \mathrm{ml})$ for $16 \mathrm{~h}$, subsequently released into fresh media, and harvested at the indicated time points. Cell lysates containing equal amounts of protein were separated by SDS-PAGE and immunoblotted with appropriate antibodies. The far left two lanes (C) show data obtained from unexposed asynchronous cells. (e) The effect of nocodazole on apoptosis in ASK $1^{-1-}$ cells was determined. After ASK1 WT and $A S K 1^{-1-}$ MEF cells were treated with nocodazole for indicated times, cells were lysed and immunoblotting was performed with anti-cleaved PARP or anti-cleaved caspase-3 antibodies. An anti-GAPDH antibody was used as a loading control for immunoblotting. The expression profiles of cleaved PARP and cleaved caspase-3 in ASK1 WT and $A S K 1^{-/-}$MEF cells were compared by scanning the immunoblots and analyzing them with LabWorks software

possible as Cdc25C p-Ser-216 levels decrease during mitosis to enhance nuclear translocation of Cdc25C, whereas ASK1 is located in the cytoplasm. However, subcellular localization of Cdc25C in nocodazole-treated cells may not be important, as nocodazole induces nuclear envelope disassembly, ${ }^{42}$ and thus ASK1 and Cdc25C could colocalize as shown in Supplementary Figure S5. We then investigated whether the binding affinity of hyperphosphorylated Cdc25C to ASK1 was different from that of hypophosphorylated Cdc25C. As shown in Figure 6c, hyperphosphorylated $\mathrm{Cdc} 25 \mathrm{C}$ had reduced interaction with ASK1 in nocodazole-treated HEK 293 cells, in contrast to the relatively tight interaction between ASK1 and hypophosphorylated Cdc25C. Moreover, hyperphosphorylated Cdc25C in HEK 293 cells treated with paclitaxel or dolastatin 15 also had lower binding affinity to ASK1 than hypophosphorylated Cdc25C (Supplementary Figure S6). Taken together, these results suggest that hyperphosphorylated and activated Cdc25C in mitotic cells does not regulate ASK1 effectively because of reduced interaction between the two proteins. 
a

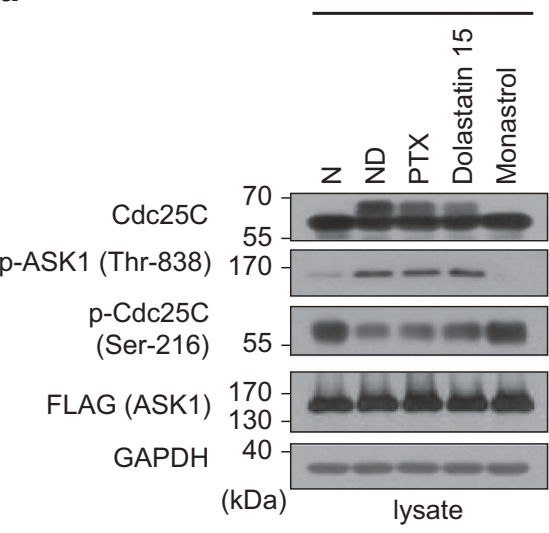

C ND $\quad 0 \quad 16(h)$

Cdc25C

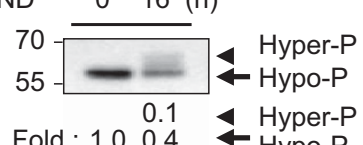

ASK1
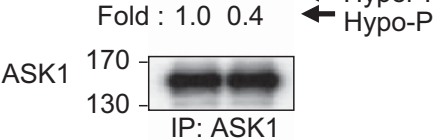

Cdc25C

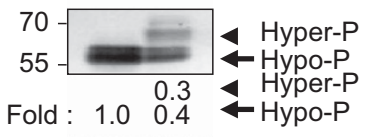

ASK1

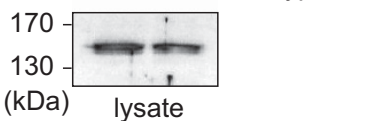

e

Interphase b

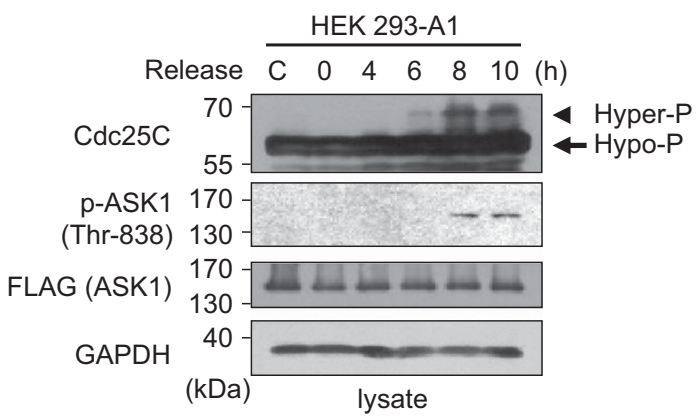

d

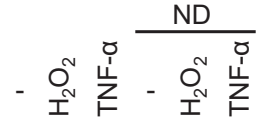

Cdc25C

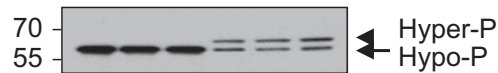

0.10 .10 .1 Hyper-P

Fold : 1.00 .90 .90 .10 .10 .1 — Hуро-P

ASK1 130

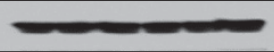

IP: $\alpha-A S K 1$

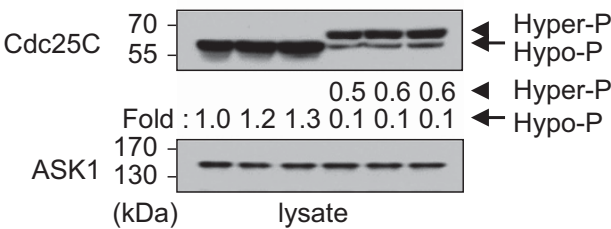

M phase-arrest

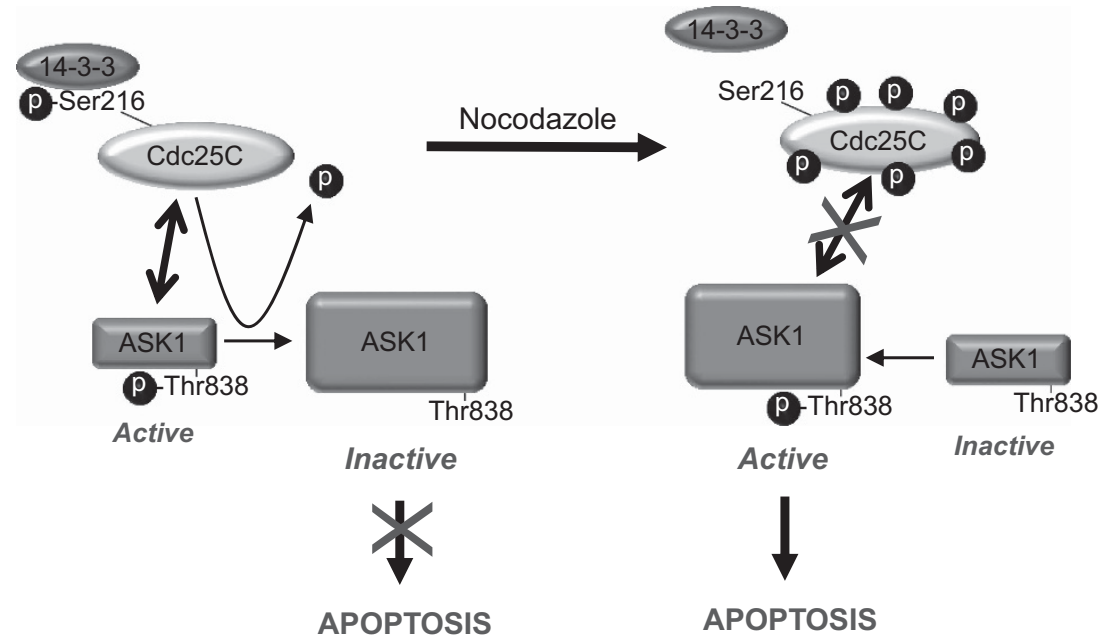

Figure 6 Hyperphosphorylation of Cdc25C leads to reduced interaction between ASK1 and Cdc25C. (a) After HEK293-A1 cells were exposed to various reagents that affect cell cycle for $16 \mathrm{~h}$, whole-cell lysates were prepared and subjected to immunoblotting using the indicated antibodies. An anti-GAPDH antibody was used as a loading control for immunoblotting. N, nontreated; PTX, paclitaxel. (b) HEK 293-A1 cells were arrested in S phase with a double thymidine block and released from arrest upon addition of fresh medium. Cell lysates were prepared at the indicated time points after release and immunoblotted with appropriate antibodies. The far left lane (C) shows data obtained from unexposed asynchronous cells. (c) After HEK 293 cells were treated with or without nocodazole ( $200 \mathrm{ng} / \mathrm{ml}$ ) for $16 \mathrm{~h}$, cells were lysed and immunoprecipitated with anti-ASK1 (F-9) agarose. Immunoprecipitates were subjected to immunoblotting analysis with anti-Cdc25C or anti-ASK1 antibody. The expression levels of Cdc25C and ASK1 were determined by immunoblotting with anti-Cdc25C and anti-ASK1 antibodies, respectively. Protein levels were analyzed by immunoblot and quantified by scanning the immunoblots and analysis with LabWorks software. Hyper-P, hyperphosphorylated Cdc25C; Hypo-P, hypophosphorylated Cdc25C. (d) After nocodazole treatment for $16 \mathrm{~h}$, lysates from untransfected HEK 293 cells treated with $\mathrm{H}_{2} \mathrm{O}_{2}(1 \mathrm{mM}, 1 \mathrm{~h})$ or TNF- $\alpha(20 \mathrm{ng} / \mathrm{ml}, 1 \mathrm{~h})$ were immunoprecipitated with anti-ASK1 (F-9) agarose. Immunoprecipitates were subjected to immunoblot analysis with anti-Cdc25C antibody. Quantitation of hypo- and hyper-phosphorylated Cdc25C was performed by analysis with LabWorks software. (e) A model for the role of Cdc25C in the regulation of ASK1 during interphase and mitotic arrest 
It is also possible that the endogenous ASK1-Cdc25C association might be affected by $\mathrm{H}_{2} \mathrm{O}_{2}$ or TNF- $a$-mediated ASK1 activation as well as hyperphosphorylation of Cdc25C. To investigate this possibility, HEK 293 cells were treated with $\mathrm{H}_{2} \mathrm{O}_{2}$ or TNF- $a$ in the presence or in the absence of nocodazole, and cell lysates were then immunoprecipitated with an anti-ASK1 antibody for subsequent immunoblotting with an anti-Cdc25C antibody. As shown in Figure 6d, ASK1Cdc25C interaction levels were not affected by $\mathrm{H}_{2} \mathrm{O}_{2}$ or TNF- $a$ treatment in both nocodazole-treated and untreated cells, suggesting that ASK1-Cdc25C association was independent of oxidative stress. In cells treated with nocodazole, the association between ASK1 and hyperphosphorylated Cdc25C was greatly reduced, whereas the interaction levels between ASK1 and hypophospho-Cdc25C were unchanged.

\section{Discussion}

Although Cdc25C has been known to be involved in the $G_{2} / M$ transition of cell cycle, the role of Cdc25C during cell cycle is largely unknown. Cdc25C has basal phosphatase activity and is located in the cytoplasm during interphase, whereas Cdc25C becomes activated by multiple phosphorylation during $\mathrm{G}_{2} / \mathrm{M}$ transition, leading to its hyperactivation toward its primary mitotic target cyclin $\mathrm{B}-\mathrm{Cdk} 1 \mathrm{complex}$. We reported here that $\mathrm{Cdc} 25 \mathrm{C}$ has two important functional features during cell cycle. First, Cdc25C inhibits ASK1 and its proapoptotic function during interphase. During interphase, hypophosphorylated Cdc25C with the basal phosphatase activity binds to ASK1 and dephosphorylates p-Thr-838 of ASK1, leading to inactivation of ASK1. Second, hyperphosphorylated Cdc25C formed during mitotic arrest loses its ability to bind to ASK1. The hyperphosphorylated form of Cdc25C, therefore, appears inactive toward ASK1, resulting in increase of ASK1 p-Thr-838 and ASK1 activation. As prolonged arrest of cells in mitosis triggers apoptosis, ${ }^{43}$ this Cdc25C function toward ASK1 may play critical roles in mitotic checkpoint that inhibits mitosis in response to abnormal stresses until the stress is removed, and induces apoptosis if the stress is persistent. In cells undergoing normal process of mitosis, however, Cdc25C hyperphosphorylation is transient and, therefore, ASK1 may not be active long enough to induce apoptosis.

The tumor suppressor p53 is a well-known key regulator of apoptosis mediated by prolonged mitotic arrest, and microtubule-stabilizing drugs, such as nocodazole and taxol, enhance p53 transcriptional activity. ${ }^{44}$ When we measured the levels of caspase-3 processing and PARP cleavage upon nocodazole treatment in $p 53^{-1-}$ cells, we also detected decrease of apoptosis in $p 53^{-/}$cells, with respect to caspase-3 processing and PARP cleavage in the presence of nocodazole, confirming the role of p53 as a regulator of mitotic arrest-mediated apoptosis (Supplementary Figure S7). The result of this study, therefore, suggests that ASK1 is another regulator of apoptosis that is mediated by prolonged mitotic arrest as nocodazole can induce Cdc25C hyperphosphorylation that leads to the release of ASK1 from Cdc25C because of reduced binding affinity. It is not clear how hyperphosphorylation of Cdc25C reduces binding affinity to ASK1. Although the precise underlying mechanism by which hypophosphorylated Cdc25C binds more strongly to ASK1 than hyperphosphorylated Cdc25C needs further study, we generated a model based on our data that may explain the mechanism by which mitotic arrest-induced hyperphosphorylation of Cdc25C contributes to ASK1 activation (Figure 6e).

Accumulating evidence strongly suggests that ASK1 is involved in cell cycle regulation. Inactivation of ASK1 signaling leads to accelerated cell growth, suggesting that ASK1 is negatively involved in cell cycle progression. ${ }^{45}$ Furthermore, JNK, a downstream factor in the ASK1 signaling pathway, inactivates Cdc25C by direct phosphorylation at Ser-168 of Cdc25C during the $\mathrm{G}_{2}$ phase. ${ }^{46}$ Therefore, these reports along with our results suggest that ASK1 signaling and Cdc25C might regulate each other during the cell cycle. Furthermore, Cdc25A, which is involved in the control of the $\mathrm{G}_{1} / \mathrm{S}$ transition, binds to a region adjacent to the ASK1 kinase domain and inhibits the kinase activity of ASK1 in a manner independent of the phosphatase activity. ${ }^{47}$ As Cdc25A and Cdc25C proteins function in different stages of the cell cycle, ${ }^{2,3,5}$ ASK1 might be regulated in several stages of the cell cycle. There are several pieces of evidence that ASK1 phosphorylation is cell cycle dependent. ${ }^{48,49}$

Although ASK1 activity is regulated at several stages of the cell cycle, it is not clear how ASK1 is involved in cross-talk between apoptosis and cell cycle progression at the molecular level. It is possible that other phosphatases at different stages of cell cycle are involved in the cross-talk. As phosphorylations of ASK1 at Ser-83 or Ser-967 are also cell cycle dependent, there might be more cell cycle-dependent phosphatases that regulate ASK1. Therefore, the regulation of ASK1 during the cell cycle via ASK1 site-specific dephosphorylation by several cell cycle-dependent phosphatases might mediate the crosstalk between cell cycle progression and ASK1-mediated apoptosis. Apoptotic cell death may be a consequence of perturbations of cell cycle regulators and the resulting activation of apoptotic factors.

\section{Materials and Methods}

Cells. $A S K 1^{-1-}$ mouse embryonic fibroblast (MEF) was obtained from Dr. Hidenori Ichijo (The University of Tokyo, Tokyo, Japan). Human embryonic kidney (HEK) 293,

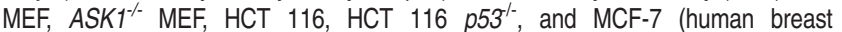
adenocarcinoma) cells were cultured in Dulbecco's modified Eagle's medium (DMEM; Invitrogen, Carlsbad, CA, USA) supplemented with heat-inactivated $10 \%$ fetal bovine serum (FBS; Invitrogen) and antibiotics (100 U/ml penicillin and $100 \mu \mathrm{g} /$ $\mathrm{ml}$ streptomycin), and maintained at $37^{\circ} \mathrm{C}$ in an incubator containing a humidified atmosphere of $5 \% \mathrm{CO}_{2}$. HEK 293 cells expressing FLAG-ASK1 (HEK 293-A1 cells) were prepared by transfecting pcDNA3.1/Zeo-FLAG-ASK1 plasmid and maintained in the presence of $100 \mu \mathrm{g} / \mathrm{ml}$ of zeocin (Invitrogen).

Plasmid construction. HA-ASK1 expression plasmid was obtained from Dr. Hidenori Ichijo. FLAG-ASK1 expression plasmid was cloned into the pCMV2FLAG vector (Sigma-Aldrich, St. Louis, MO, USA) or pcDNA3.1/Zeo plasmid (Invitrogen). The FLAG- or HA-tagged Cdc25C WT and Cdc25C mutant (C377S) were constructed in pcDNA3.1/Zeo plasmid (Invitrogen). His-Cdc25C WT and HisCdc25C mutant (C377S) that express the catalytic domain (residues 207-400) and His-MKK6 were constructed in pET28a plasmid (Novagen, Darmstadt, Germany) for protein expressions in E. coli.

Antibodies and reagents. Polyclonal anti-phospho-ASK1 (Ser-83), anti-phospho-ASK1 (Thr-845, corresponding to Thr-838 of human ASK1), anti-phospho-ASK1 (Ser-967), anti-JNK, anti-phospho-JNK (Thr-183/Tyr-185), anti-p38, anti-phospho-p38 (Thr-180/Tyr-182), anti-MKK4, anti-phospho-MKK4 (Ser-257/Thr-261), anti-MKK7, anti-phospho-MKK7 (Ser-271/Thr-275), anti-COX IV, anti-cytochrome $c$, anti-Cdc25C, anti-caspase-9, anti-caspase-3, and 
anti-cleaved PARP antibodies were purchased from Cell Signaling Technology (Beverly, MA, USA). Anti-ASK1 (F-9) agarose bead, anti-ASK1 (H-300), anti-p53, anti-glyceraldehyde 3-phosphate dehydrogenase (GAPDH), anti-HA antibodies, and dolastatin 15 were from Santa Cruz Biotechnology (Santa Cruz, CA, USA). AntiFLAG M2 agarose beads, cycloheximide, nocodazole (ND), paclitaxel (PTX), antiFLAG M2, and anti-tubulin antibodies were from Sigma-Aldrich. Monastrol was from Abcam (Cambridge, MA, USA).

Recombinant Cdc25C protein expression and purification. After E. coli BL21 (DE3)RIL was transformed with pET28a-His-Cdc25C WT or pET28aHis-Cdc25C mutant (C377S), cells were grown on LB medium containing kanamycin and $0.2 \mathrm{mM}$ isopropyl- $\beta$-D-1 thiogalactopyranoside at $18^{\circ} \mathrm{C}$ for $16 \mathrm{~h}$. Cells were harvested and resuspended in lysis buffer $(50 \mathrm{mM}$ Tris- $\mathrm{HCl}(\mathrm{pH} 7.5)$, $500 \mathrm{mM} \mathrm{NaCl}, 1 \mathrm{mM}$ phenylmethanesulfonyl fluoride (PMSF), $4 \mathrm{mM}$ 2-mercaptoethanol, and $5 \%$ (v/v) glycerol) and then lysed by sonication. The cell extracts were centrifuged at 16000 r.p.m. for $50 \mathrm{~min}$ and the supernatant was subjected to Ni-NTA agarose affinity chromatography. The Cdc25C phosphatase bound to the affinity gel was eluted by imidazole gradient method and frozen at $-80^{\circ} \mathrm{C}$ in a buffer containing $25 \mathrm{mM}$ Tris- $\mathrm{HCl}(\mathrm{pH} 7.5), 200 \mathrm{mM} \mathrm{NaCl}, 10 \mathrm{mM}$ 2-mercaptoethanol, and 5\% (v/v) glycerol until enzyme assay.

Transfection of DNA and siRNA. Cells plated 1 day before transfection were transfected with DNA using LipofectAMINE reagents (Invitrogen) according to the manufacturer's instructions. After transfection, cells were cultured for $24-48 \mathrm{~h}$ before harvesting.

For RNA interference of $\mathrm{Cdc} 25 \mathrm{C}$, cells grown at $40 \%$ confluences were transfected with siRNA of Cdc25C (Bioneer Corporation, Daejeon, South Korea) using LTX transfection reagent according to the manufacturer's protocol (Invitrogen). The siRNA target sequences of Cdc25C were $5^{\prime}$-CUACUUUCUCUCCUCUUGU-3' (dTdT) (\#1) or 5'-CCUGAAAGAUCAAGAAGCA-3' (dTdT) (\#2). The negative control siRNA used was purchased from Bioneer.

Protein binding assays and immunoblotting analysis. After HEK 293 cells were cotransfected with ASK1 and Cdc25C expression plasmids for $48 \mathrm{~h}$ cells were washed twice with phosphate-buffered saline (PBS) buffer and lysed in PTP lysis buffer (0.5\% NP-40, 0.5\% Triton X-100, $150 \mathrm{mM} \mathrm{NaCl}, 20 \mathrm{mM}$ Tris-HCl (pH 8.0), $1 \mathrm{mM}$ EDTA, $1 \%$ glycerol, $1 \mathrm{mM}$ phenylmethylsulfonyl fluoride (PMSF), and $1 \mu \mathrm{g} / \mathrm{ml}$ aprotinin) for $30 \mathrm{~min}$ at $4{ }^{\circ} \mathrm{C}$. Cleared cell lysates from centrifugation were incubated with $20 \mu \mathrm{l}$ of anti-FLAG M2 agarose at $4^{\circ} \mathrm{C}$ for $4 \mathrm{~h}$. Anti-FLAG M2 agarose-bound proteins were washed with PTP lysis buffer, resuspended with protein sample buffer, boiled at $100^{\circ} \mathrm{C}$ for $5 \mathrm{~min}$, subjected to SDS-PAGE, and subsequently transferred onto nitrocellulose (NC) membrane. The membranes were then blocked with $5 \%$ skim milk/TBS for $1 \mathrm{~h}$ and incubated with the appropriate primary antibodies and horseradish peroxidase (HRP)-conjugated secondary antibodies at room temperature. Following extensive washing, protein bands were visualized using enhanced chemiluminescence (ECL) western blotting detection reagents (Pierce, Rockford, IL, USA).

To examine in vivo interaction between the endogenous proteins, cell lysates were prepared from HEK 293 cells as described above and subjected to immunoprecipitation with an anti-ASK1 antibody or with Cdc25C-specific mouse lgG followed by incubation with protein $A / G$ agarose for $16 \mathrm{~h}$ at $4^{\circ} \mathrm{C}$. The bound proteins were analyzed by immunoblotting with anti-ASK1 antibody or anti-Cdc25C antibody.

In vitro kinase assays. For ASK 1 kinase activity assay, transfected HEK 293 cells were lysed with the lysis buffer containing $0.5 \%$ NP-40, 0.5\% Triton X-100, $150 \mathrm{mM} \mathrm{NaCl}, 20 \mathrm{mM}$ Tris-HCl (pH 8.0), $1 \mathrm{mM}$ EDTA, 1\% glycerol, $1 \mathrm{mM}$ PMSF, and $1 \mu \mathrm{g} / \mathrm{ml}$ aprotinin. Cleared cell lysates were incubated with anti-FLAG M2 agarose at $4^{\circ} \mathrm{C}$ for $4 \mathrm{~h}$ and the FLAG immunoprecipitates were assayed for the ASK1 kinase activities by using His-MKK6 as a substrate. Kinase assay was performed at $30^{\circ} \mathrm{C}$ for $30 \mathrm{~min}$ in the final reaction mixture $-1 \mu \mathrm{Ci}\left[\gamma_{-}{ }^{32} \mathrm{P}\right]-\mathrm{ATP}$ in kinase reaction buffer (20 mM Tris- $\mathrm{HCl}$ (pH 7.5), $20 \mathrm{mM} \mathrm{MgCl}$, and $0.1 \mathrm{mM} \mathrm{Na}_{3} \mathrm{VO}_{4}$ ). Phosphorylated substrates were determined using SDS-PAGE and autoradiography.

For autophosphorylation assays, kinase assays were performed as described above except that no substrate was added.

In vitro phosphatase assays. HEK 293-A1 cells were treated with $1 \mathrm{mM}$ $\mathrm{H}_{2} \mathrm{O}_{2}$ for $30 \mathrm{~min}$, and cell lysates were prepared by PTP lysis buffer. Cleared cell lysates were immunoprecipitated with anti-FLAG M2 agarose and the beads were washed twice with PTP lysis buffer. The beads were then added with $0.5 \mu \mathrm{g}$ of
His-Cdc25C WT or Cdc25C mutant (C377S) in $20 \mu \mathrm{l}$ PTP reaction buffer (100 mM Tris- $\mathrm{HCl}(\mathrm{pH} 7.5), 40 \mathrm{mM} \mathrm{NaCl}$, and $1 \mathrm{mM} \mathrm{DTT}$ ), and reaction mixtures were incubated at $30^{\circ} \mathrm{C}$ for $0-60 \mathrm{~min}$. Phosphatase reaction was stopped by adding SDS sample buffer. The beads were then resolved on SDS-PAGE followed by electroblotting onto NC membranes and analyzed by immunoblotting with anti-phospho-ASK1 antibodies.

For phosphatase assay with Cdc25C, HEK 293 cells were lysed in PTP lysis buffer and subjected to centrifugation to remove insoluble material. The supernatants were immunoprecipitated using an appropriate antibody. Immunoprecipitates were washed twice with PTP lysis buffer. Each immune complex was assayed at $30^{\circ} \mathrm{C}$ in $100 \mu$ l of reaction buffer containing $100 \mathrm{mM}$ Tris- $\mathrm{HCl}(\mathrm{pH} 7.5), 40 \mathrm{mM} \mathrm{NaCl}, 1 \mathrm{mM}$ DTT, $20 \%$ glycerol, and $500 \mu \mathrm{M}$ 3-O-methylfluorescein phosphate (OMFP; Sigma-Aldrich). The amount of OMFP was determined by the absorbance change at $490 \mathrm{~nm}$ or fluorescence change of excitation at $485 \mathrm{~nm}$ and emission at $525 \mathrm{~nm}$. The phosphatase activity of recombinant $\mathrm{Cdc} 25 \mathrm{C}$ was assayed as described above.

Cell cycle analysis. To determine cell cycle distribution analysis, $5 \times 10^{5}$ cells were plated in $60 \mathrm{~mm}$ dishes and treated with $200 \mathrm{ng} / \mathrm{ml}$ nocodazole for times indicated. For $\mathrm{G}_{2} / \mathrm{M}$ fraction quantification, cells were fixed with $70 \%$ ethanol, and the cells were washed with PBS three times and then incubated with RNase $A$ and propidium iodide at room temperature for $30 \mathrm{~min}$. Cells (at least $2 \times 10^{4}$ ) were analyzed using FACSCalibur (Becton Dickinson, Franklin Lakes, NJ, USA) and CellQuest software (Becton Dickinson).

Double thymidine block. Cells were plated in $60 \mathrm{~mm}$ dishes as $40 \%$ confluences at first thymidine block and treated with $5 \mu \mathrm{M}$ thymidine for $19 \mathrm{~h}$. Cells were washed with warm PBS 2 times and incubated with fresh medium (10\% FBS and $1 \%$ penicillin and streptomycin) for $9 \mathrm{~h}$, and then $5 \mu \mathrm{M}$ thymidine was added. After $16 \mathrm{~h}$ of incubation, cells were released to normal cell cycle by replacing with fresh medium (10\% FBS and 1\% penicillin and streptomycin) as the times indicated. Released cells for each time were harvested and subsequently subjected to FACS or immunoblotting analysis.

Cell viability assay. Cell viability was determined using a CCK-8 cell viability assay kit (Dojindo Molecular Technologies, Rockville, MD, USA). Briefly, transfected MEF cells in exponential growth were harvested by trypsinization and seeded at a concentration of $3 \times 10^{3}$ cells/well into 96-well plates, and were allowed to stand overnight for attachment. Cells were stimulated with $1 \mathrm{mM} \mathrm{H}_{2} \mathrm{O}_{2}$ for $4 \mathrm{~h}$. CCK-8 solution ( $10 \mu \mathrm{l}$ per $100 \mu \mathrm{l}$ of medium in each well) was added, the plates were incubated at $37^{\circ} \mathrm{C}$ for $30-60 \mathrm{~min}$, and the absorbance of each well was measured at $450 \mathrm{~nm}$ using a microplate reader.

Measurement of caspase-3 activity and detection of caspase9. Caspase-3 activity was measured as described previously. ${ }^{21}$ Briefly, MEF cells $\left(2 \times 10^{6} / 60 \mathrm{~mm}\right.$ plate) were transfected with both FLAG-ASK1 and HA-Cdc25C expression plasmids. After $24 \mathrm{~h}$ of transfection, cells were transferred to $100 \mathrm{~mm}$ plates and grown to $80 \%$ confluence. Then, cells were exposed to $1 \mathrm{mM} \mathrm{H}_{2} \mathrm{O}_{2}$ for $4 \mathrm{~h}$ before collection for measurement.

For detection of caspase-9, $\mathrm{H}_{2} \mathrm{O}_{2}$-treated cell lysates $\left(1 \mathrm{mM} \mathrm{H}_{2} \mathrm{O}_{2}\right.$ for $4 \mathrm{~h}$ ) were prepared and analyzed by immunoblotting with an anti-caspase-9 antibody and HRP-coupled monoclonal anti-rabbit IgG antibody (Sigma-Aldrich).

Detection of cytochrome $\boldsymbol{c}$ release. MEF cells were transfected with HA-ASK1 or HA-Cdc25C expression plasmid. After treatment with $0.5 \mathrm{mM} \mathrm{H}_{2} \mathrm{O}_{2}$ for $4 \mathrm{~h}$, cytosolic and mitochondrial fractions were separated with the Qproteome Cell Compartment kit (QIAGEN, Valencia, CA, USA). The presence of cytochrome $c$ in the cytosolic fraction was assessed by immunoblotting with an anti-cytochrome $c$ antibody.

Reverse transcription-PCR. Total RNAs were prepared from cells using Trizol (Roche, Basal, Switzerland) and reverse transcription was performed using M-MLV (Invitrogen). PCR for human Cdc25C was carried out using the following primers: forward 5'-GAACAGGCCAAGACTGAAGC-3' and reverse 5'-GCCCCTGG TTAGAATCTTC C-3'.

Measurement of regulation of Cdc25C by ASK1. FLAG-ASK1 was transfected to HEK 293 cells in a dose-dependent manner. After $48 \mathrm{~h}$ of incubation, $40 \mu \mathrm{g} / \mathrm{ml}$ cycloheximide was added with serum-free medium as the times indicated. 
Cell lysates were prepared and subsequently immunoblotted with anti-Cdc25C and anti-p-Cdc25C antibodies.

Subcellular fractionation. HEK 293 cells were treated with nocodazole $(200 \mathrm{ng} / \mathrm{ml})$ for $16 \mathrm{~h}$ and total cells were collected by scrapping the dishes. After washing with cold PBS 2 times, cells were resuspended with buffer A $(10 \mathrm{mM}$ HEPES (pH 7.9), $10 \mathrm{mM} \mathrm{KCl}$, and $10 \mathrm{mM}$ EDTA) and placed on $4{ }^{\circ} \mathrm{C}$ for $10 \mathrm{~min}$ with rotation (200 r.p.m.). The supernatants after centrifugation at 13000 r.p.m. for 3 min were collected as cytosolic fraction and the remained pellets were subjected to wash with buffer A 2 times. After absolute removal of supernatants, pellets were resuspended with buffer $B(20 \mathrm{mM}$ HEPES, $400 \mathrm{mM} \mathrm{NaCl}, 1 \mathrm{mM}$ EDTA, and $10 \%$ glycerol) and placed on ice for 30 min with vigorous vortexing for $10 \mathrm{~s}$ at every 5 min. The supernatants after centrifugation at 13000 r.p.m. for 5 min were collected as nuclear fraction.

CIP treatment of hyperphosphorylated Cdc25C. Total cell lysates from nocodazole-treated or untreated cells were prepared using PTP lysis buffer. Equal quantities of lysates were incubated with $\mathrm{CIP}$ for $30 \mathrm{~min}$ at $30^{\circ} \mathrm{C}$ and the reaction was stopped by adding SDS sample loading buffer. The protein samples were analyzed by immunoblotting with anti-Cdc25C antibody.

Experimental replicates and statistical analysis. All of the figures shown here are representative of at least three experimental repeats. For statistical analysis, differences between experimental conditions were assessed by Student's $t$-test. $P<0.05$ considered to be statistically significant. In all instances, the means of data from three independent experiments were analyzed.

\section{Conflict of Interest}

The authors declare no conflict of interest.

Acknowledgements. We thank Dr. Hidenori Ichijo for HA-ASK1 expression plasmid and $A S K{ }^{1-2}$ MEF. This research was supported by the National Research Foundation of Korea (NRF) grant funded by the Ministry of Science, ICT \& Future Planning (NRF-2011-0030029, NRF-2011-0028172, NRF-2012R1A1B3001937, and NRF-2012R1A2A2A01047338).

1. Strausfeld U, Labbe JC, Fesquet D, Cavadore JC, Picard A, Sadhu K et al. Dephosphorylation and activation of a p34cdc2/cyclin B complex in vitro by human CDC25 protein. Nature 1991; 351: 242-245.

2. Hoffmann I, Draetta G, Karsenti E. Activation of the phosphatase activity of human cdc25A by a cdk2-cyclin $E$ dependent phosphorylation at the G1/S transition. EMBO J 1994; 13: 4302-4310.

3. Jinno S, Suto K, Nagata A, Igarashi M, Kanaoka $Y$, Nojima $\mathrm{H}$ et al. Cdc25A is a novel phosphatase functioning early in the cell cycle. EMBO J 1994; 13: 1549-1556.

4. Cans C, Ducommun B, Baldin V. Proteasome-dependent degradation of human CDC25B phosphatase. Mol Biol Rep 1999; 26: 53-57.

5. Hoffmann I, Clarke PR, Marcote MJ, Karsenti E, Draetta G. Phosphorylation and activation of human cdc25-C by cdc2-cyclin B and its involvement in the self-amplification of MPF at mitosis. EMBO J 1993; 12: 53-63.

6. Kristjansdottir K, Rudolph J. Cdc25 phosphatases and cancer. Chem Biol 2004; 11: 1043-1051.

7. Dalal SN, Schweitzer CM, Gan J, DeCaprio JA. Cytoplasmic localization of human cdc25C during interphase requires an intact 14-3-3 binding site. Mol Cell Biol 1999; 19: 4465-4479.

8. Lopez-Girona A, Furnari B, Mondesert O, Russell P. Nuclear localization of Cdc25 is regulated by DNA damage and a 14-3-3 protein. Nature 1999; 397: 172-175.

9. Kumagai A, Yakowec PS, Dunphy WG. 14-3-3 proteins act as negative regulators of the mitotic inducer Cdc25 in Xenopus egg extracts. Mol Biol Cell 1998; 9: 345-354.

10. Peng CY, Graves PR, Thoma RS, Wu Z, Shaw AS, Piwnica-Worms H. Mitotic and G2 checkpoint control: regulation of 14-3-3 protein binding by phosphorylation of Cdc25C on serine-216. Science 1997; 277: 1501-1505.

11. O'Connor PM, Ferris DK, Hoffmann I, Jackman J, Draetta G, Kohn KW. Role of the cdc $25 \mathrm{C}$ phosphatase in G2 arrest induced by nitrogen mustard. Proc Natl Acad Sci USA 1994; 91 : 9480-9484.

12. Song JJ, Rhee JG, Suntharalingam M, Walsh SA, Spitz DR, Lee YJ. Role of glutaredoxin in metabolic oxidative stress. Glutaredoxin as a sensor of oxidative stress mediated by $\mathrm{H} 2 \mathrm{O} 2$. J Biol Chem 2002; 277: 46566-46575.

13. Saitoh M, Nishitoh H, Fujii M, Takeda K, Tobiume K, Sawada Y et al. Mammalian thioredoxin is a direct inhibitor of apoptosis signal-regulating kinase (ASK) 1. EMBO J 1998; 17: 2596-2606.
14. Liu $\mathrm{H}$, Nishitoh $\mathrm{H}$, Ichijo $\mathrm{H}$, Kyriakis JM. Activation of apoptosis signal-regulating kinase (ASK1) by tumor necrosis factor receptor-associated factor 2 requires prior dissociation of the ASK1 inhibitor thioredoxin. Mol Cell Biol 2000; 20: 2198-2208.

15. Chang HY, Nishitoh H, Yang X, Ichijo H, Baltimore D. Activation of apoptosis signal-regulating kinase 1 (ASK1) by the adapter protein Daxx. Science 1998; 281: 1860-1863.

16. Nishitoh H, Matsuzawa A, Tobiume K, Saegusa K, Takeda K, Inoue K et al. ASK1 is essential for endoplasmic reticulum stress-induced neuronal cell death triggered by expanded polyglutamine repeats. Genes Dev 2002; 16: 1345-1355.

17. Ichijo H, Nishida E, Irie K, ten Dijke P, Saitoh M, Moriguchi T et al. Induction of apoptosis by ASK1, a mammalian MAPKKK that activates SAPK/JNK and p38 signaling pathways. Science 1997; 275: 90-94.

18. Gotoh Y, Cooper JA. Reactive oxygen species- and dimerization-induced activation of apoptosis signal-regulating kinase 1 in tumor necrosis factor-alpha signal transduction. J Biol Chem 1998; 273: 17477-17482.

19. Nishitoh H, Saitoh M, Mochida Y, Takeda K, Nakano H, Rothe M et al. ASK1 is essential for JNK/SAPK activation by TRAF2. Mol Cell 1998; 2: 389-395.

20. Cho S, Ko HM, Kim JM, Lee JA, Park JE, Jang MS et al. Positive regulation of apoptosis signal-regulating kinase 1 by hD53L1. J Biol Chem 2004; 279: 16050-16056.

21. Lee JA, Park JE, Lee DH, Park SG, Myung PK, Park BC et al. G1 to S phase transition protein 1 induces apoptosis signal-regulating kinase 1 activation by dissociating 14-3-3 from ASK1. Oncogene 2008; 27: 1297-1305.

22. Park JE, Park BC, Kim HA, Song M, Park SG, Lee do H et al. Positive regulation of apoptosis signal-regulating kinase 1 by dual-specificity phosphatase 13A. Cell Mol Life Sci 2010; 67: 2619-2629.

23. Matsuura H, Nishitoh H, Takeda K, Matsuzawa A, Amagasa T, Ito M et al. Phosphorylationdependent scaffolding role of JSAP1/JIP3 in the ASK1-JNK signaling pathway. A new mode of regulation of the MAP kinase cascade. J Biol Chem 2002; 277: 40703-40709.

24. Zhang L, Chen J, Fu H. Suppression of apoptosis signal-regulating kinase 1-induced cell death by 14-3-3 proteins. Proc Natl Acad Sci USA 1999; 96: 8511-8515.

25. Zhang R, Luo D, Miao R, Bai L, Ge Q, Sessa WC et al. Hsp90-Akt phosphorylates ASK1 and inhibits ASK1-mediated apoptosis. Oncogene 2005; 24: 3954-3963.

26. Fujii K, Goldman EH, Park HR, Zhang L, Chen J, Fu H. Negative control of apoptosis signal-regulating kinase 1 through phosphorylation of Ser-1034. Oncogene 2004; 23: 5099-5104.

27. Kim AH, Khursigara G, Sun X, Franke TF, Chao MV. Akt phosphorylates and negatively regulates apoptosis signal-regulating kinase 1. Mol Cell Biol 2001; 21: 893-901.

28. Morita K, Saitoh M, Tobiume K, Matsuura H, Enomoto S, Nishitoh $\mathrm{H}$ et al. Negative feedback regulation of $A S K 1$ by protein phosphatase 5 (PP5) in response to oxidative stress. EMBO J 2001; 20: 6028-6036.

29. Gu JJ, Wang Z, Reeves R, Magnuson NS. PIM1 phosphorylates and negatively regulates ASK1-mediated apoptosis. Oncogene 2009; 28: 4261-4271.

30. Tobiume K, Saitoh M, Ichijo H. Activation of apoptosis signal-regulating kinase 1 by the stress-induced activating phosphorylation of pre-formed oligomer. J Cell Physiol 2002; 191: 95-104.

31. Yu L, Min W, He Y, Qin L, Zhang H, Bennett AM et al. JAK2 and SHP2 reciprocally regulate tyrosine phosphorylation and stability of proapoptotic protein ASK1. J Biol Chem 2009; 284: 13481-13488.

32. Tamura S, Toriumi S, Saito J, Awano K, Kudo TA, Kobayashi T. PP2C family members play key roles in regulation of cell survival and apoptosis. Cancer Sci 2006; 97: 563-567.

33. Min W, Lin Y, Tang S, Yu L, Zhang H, Wan T et al. AlP1 recruits phosphatase PP2A to ASK1 in tumor necrosis factor-induced ASK1-JNK activation. Circ Res 2008; 102: 840-848.

34. Kuo PL, Chen CY, Hsu YL. Isoobtusilactone A induces cell cycle arrest and apoptosis through reactive oxygen species/apoptosis signal-regulating kinase 1 signaling pathway in human breast cancer cells. Cancer Res 2007; 67: 7406-7420.

35. Finkel T. Redox-dependent signal transduction. FEBS Lett 2000; 476: 52-54.

36. Alonso A, Sasin J, Bottini N, Friedberg I, Friedberg I, Osterman A et al. Protein tyrosine phosphatases in the human genome. Cell 2004; 117: 699-711.

37. Savitsky PA, Finkel T. Redox regulation of Cdc25C. J Biol Chem 2002; 277: 20535-20540.

38. Hatai T, Matsuzawa A, Inoshita S, Mochida Y, Kuroda T, Sakamaki K et al. Execution of apoptosis signal-regulating kinase 1 (ASK1)-induced apoptosis by the mitochondriadependent caspase activation. J Biol Chem 2000; 275: 26576-26581.

39. Bulavin DV, Higashimoto Y, Demidenko ZN, Meek S, Graves P, Phillips C et al. Dual phosphorylation controls Cdc25 phosphatases and mitotic entry. Nat Cell Biol 2003; 5: $545-551$.

40. Bonnet J, Mayonove P, Morris MC. Differential phosphorylation of Cdc $25 \mathrm{C}$ phosphatase in mitosis. Biochem Biophys Res Commun 2008; 370: 483-488.

41. Bumbasirevic V, Skaro-Milic A, Mircic A, Djuricic B. Apoptosis induced by microtubule disrupting drugs in normal murine thymocytes in vitro. Scanning Microsc 1995; 9: 509-516 discussion 516-508.

42. Tishler RB, Lamppu DM, Park S, Price BD. Microtubule-active drugs taxol, vinblastine, and nocodazole increase the levels of transcriptionally active p53. Cancer Res 1995; 55: 6021-6025.

43. Georgatos SD, Pyrpasopoulou A, Theodoropoulos PA. Nuclear envelope breakdown in mammalian cells involves stepwise lamina disassembly and microtubule-drive deformation of the nuclear membrane. J Cell Sci 1997; 110: 2129-2140. 
44. Blagosklonny MV. Mitotic arrest and cell fate: why and how mitotic inhibition of transcription drives mutually exclusive events. Cell Cycle 2007; 6: 70-74.

45. Xie D, Gore C, Zhou J, Pong RC, Zhang H, Yu L et al. DAB2IP coordinates both PI3K-Akt and ASK1 pathways for cell survival and apoptosis. Proc Natl Acad Sci USA 2009; 106: 19878-19883.

46. Gutierrez GJ, Tsuji T, Cross JV, Davis RJ, Templeton DJ, Jiang W et al. JNK-mediated phosphorylation of $\mathrm{Cdc} 25 \mathrm{C}$ regulates cell cycle entry and $\mathrm{G}(2) / \mathrm{M}$ DNA damage checkpoint. J Biol Chem 2010; 285: 14217-14228.
47. Zou X, Tsutsui T, Ray D, Blomquist JF, Ichijo H, Ucker DS et al. The cell cycle-regulatory CDC25A phosphatase inhibits apoptosis signal-regulating kinase 1. Mol Cell Biol 2001; 21: 4818-4828.

48. Zuo Z, Dean NM, Honkanen RE. Serine/threonine protein phosphatase type 5 acts upstream of p53 to regulate the induction of p21(WAF1/Cip1) and mediate growth arrest. J Biol Chem 1998; 273: 12250-12258.

49. Yun SJ, Tucker DF, Kim EK, Kim MS, Do KH, Ha JM et al. Differential regulation of Akt/protein kinase B isoforms during cell cycle progression. FEBS Lett 2009; 583: 685-690.

Supplementary Information accompanies this paper on Cell Death and Differentiation website (http://www.nature.com/cdd) 